\title{
An unusual presentation of familial Mediterranean fever with co-existing polyarteritis nodosa and acute post-streptococcal glomerulonephritis
}

\author{
yesim ozdemir atikel ${ }^{1}$, Betul Emine Derinkuyu ${ }^{1}$, and Sevcan Bakkaloğlu ${ }^{1}$ \\ ${ }^{1}$ Gazi University Faculty of Medicine
}

November 23, 2021

\begin{abstract}
The homozygous M694V mutation in the MEFV gene may cause an augmented response to the streptococcal infection that plays a role in the development of APSGN and PAN. Both clinical manifestations may occur simultaneously after streptococcal infection in a child who is previously healthy but carries a MEFV mutation.
\end{abstract}

\section{INTRODUCTION}

Familial Mediterranean fever (FMF) is an autoinflammatory disease, associated with mutations in the Mediterranean fever (MEFV) gene with an autosomal recessive pattern of inheritance, and mainly affects populations of eastern Mediterranean descent ${ }^{1}$. It is characterized by recurrent self-limited attacks of fever and serosal inflammation as well as the development of amyloidosis ${ }^{1,2}$. Patients with FMF may also have non-amyloid renal involvement including typical acute post-streptococcal glomerulonephritis (APSGN $)^{3}$. APSGN is an important non-suppurative, immunologically mediated complication of streptococcal infection ${ }^{4}$ and presents with the sudden onset of gross hematuria, edema, and hypertension with variable degrees of renal impairment ${ }^{5}$. Vasculitic diseases such as polyarteritis nodosa (PAN) also affect the kidneys in $\mathrm{FMF}^{6}$. PAN is a primary multisystem inflammatory disorder characterized by acute necrotizing vasculitis of the small and medium-sized visceral arteries and their branches with a pauci-immune pattern ${ }^{7,8}$, and it may develop in children with $\mathrm{FMF}^{7,9}$. Here, we report a previously healthy patient, newly diagnosed with FMF and with co-existing APSGN and PAN.

\section{CASE PRESENTATION}

A 7-year-old Turkish girl was admitted to our hospital with fever, gross hematuria, abdominal pain, and myalgia for four days before admission. She had been taking ceftriaxone for three days on suspicion of a urinary tract infection, and there was a history of throat infection three weeks before. There were no recurrent attacks of fever, abdominal pain, arthralgia, or chest pain. Past medical history was unremarkable with no consanguinity. On admission, there were bilateral lower extremity pitting edema, generalized muscle tenderness, and abdominal tenderness with guarding on physical examination. The patient was in the $>95^{\text {th }}$ percentile for blood pressure, and her body temperature was $38.7^{\circ} \mathrm{C}$. Laboratory tests showed hemoglobin at $10 \mathrm{~g} / \mathrm{dL}$; white blood cells at $11700 / \mathrm{mm}^{3}$; platelets at $352000 / \mathrm{mm}^{3}$; C-reactive protein $(\mathrm{CRP})$ at 185 $\mathrm{mg} / \mathrm{L}$; erythrocyte sedimentation rate $(\mathrm{ESR})$ at $68 \mathrm{~mm} /$ hour; creatinine at $0.4 \mathrm{mg} / \mathrm{dL}$; and albumin at $2.4 \mathrm{~g} / \mathrm{dL}$. Liver function tests were normal. Urinalysis revealed 2210 red blood cells per high power field which were dysmorphic. The patient's 24-hour urine protein excretion was at the nephrotic level (1045 mg, $55 \mathrm{mg} / \mathrm{m}^{2} / \mathrm{h}$ ). Chest X-ray and abdominopelvic and doppler ultrasounds were unremarkable. Viral serology, including hepatitis B, hepatitis C, HIV, EBV, and cytomegalovirus, was negative. Complement component 
3 (C3) was $48.3 \mathrm{mg} / \mathrm{dL}$ while complement component 4, anti-nuclear antibodies, anti-double-stranded DNA antibodies, and antineutrophil cytoplasmic antibodies (ANCAs) were normal. There was a significant increase in antistreptolysin O level (3886 IU/ml), suggesting group A Streptococcus (GAS) infection.

Based on these findings, the patient was first diagnosed with APSGN. Hypervolemia regressed with furosemide in addition to salt and fluid restriction. Since acute phase reactants were still high, and she had a resistant fever, antibiotic treatment was replaced with clindamycin. Subsequently, we suspected a co-existing vasculitic disease as we did not observe clinical improvement, and we therefore performed abdominal computed tomography (CT) angiography. The maximum intensity projection images obtained from the CT data showed multiple microaneurysms in the peripheral branches of the left hepatic artery compatible with medium-sized vessel vasculitis (Figures 1a and $1 \mathrm{~b}$ ). The abdominal aorta and the iliac, celiac, superior mesenteric, and both renal arteries were normal. These angiographic findings confirmed a diagnosis of PAN. Steroid treatment was initiated and three doses of pulse methylprednisolone $(20 \mathrm{mg} / \mathrm{kg} /$ dose $)$ followed by $2 \mathrm{mg} / \mathrm{kg} /$ day oral prednisolone were administered. Following the first pulse steroid dose, complaints dramatically reduced. CRP was $21 \mathrm{mg} / \mathrm{L}$ by the third dose, and C3 had returned to normal levels by the fourth week. There was no progressive decline in renal function, and so no renal biopsy was performed.

Since glomerulonephritis is not expected in PAN but both clinical conditions can be seen in FMF, we performed analysis of the MEFV gene that revealed a homozygous M694V mutation, and colchicine was started. Following clinical and laboratory remission, steroid treatment was gradually tapered and ceased at the $18^{\text {th }}$ month. At three years follow-up, the patient continues with colchicine treatment only, is now wholly symptom free, and has normal laboratory parameters with no proteinuria.

\section{DISCUSSION}

We have described a rare presentation of FMF with co-existing systemic PAN and APSGN preceded by GAS following a throat infection. In PAN, arterioles, venules, and capillaries (including the glomerular capillary) are characteristically not involved ${ }^{7,8,10}$. Unlike other systemic vasculitides which are idiopathic or autoimmune, PAN has several potential triggers including viruses, such as hepatitis B, hepatitis C, HIV, cytomegalovirus, EBV, and Parvovirus B19, as well as bacteria. ${ }^{8}$. Patients with PAN may have a defect in handling streptococcal infections which can lead to the development of circulating immune complexes with arterial or glomerular damage ${ }^{11}$.

The diagnosis of childhood PAN requires histopathologic confirmation of necrotizing vasculitis or angiographic abnormalities as mandatory criteria ${ }^{7}$, but, because of the potential development of microaneurysms and hemorrhage, kidney and liver biopsies should only be performed when other approaches have been unsuccessful ${ }^{8}$. Necrotizing vasculitis can result in luminal arterial changes, observable by arteriography, and a diagnosis of PAN can be established in this way ${ }^{8,12,13}$. The classical arteriographic finding is aneurysmal dilatation, but other luminal changes such as beaded tortuosity, abrupt cut-offs, tapering stenosis of smaller vessels, and pruning of the peripheral renal arterial tree may also suggest vasculitis ${ }^{7}$.

Liver involvement occurs in $16 \%$ to $56 \%$ of patients, and clinical findings related to liver disease are rare. Necrotizing vasculitis may be seen in liver biopsy whereas hepatic arteriograms may show caliber changes with corkscrew vessels and distal microaneurysms ${ }^{14}$. In the present case, the maximum intensity projection images obtained from CT angiography showing multiple microaneurysms in the peripheral branches of the left hepatic artery to confirm the PAN diagnosis. Treatment includes induction with high doses of corticosteroids and cyclophosphamide and maintenance therapy with low-dose prednisolone and azathioprine ${ }^{7}$. In our patient, the abdominal aorta and iliac, celiac, superior mesenteric, and renal arteries were intact, and she responded dramatically to steroid treatment. We did not therefore administer cyclophosphamide or azathioprine.

As previously mentioned, capillaries are not involved in PAN, and so glomerulonephritis is not expected in its course. On the other hand, however, patients with FMF may have non-amyloid renal involvement characterized by transient or persistent hematuria, proteinuria, typical APSGN, and various other types of glomerulonephritis ${ }^{3}$. It has also been shown that vasculitic diseases such as PAN affect the kidney in FMF 
${ }^{6}$, and there is an association between childhood PAN and FMF ${ }^{6,9,15}$. Mutations in the MEFV gene may provide a basis for PAN development by forming a proinflammatory state and prompting an exaggerated response to streptococcal infections ${ }^{9}$, and homozygosity of the M694V mutation has been found to be associated with the most serious phenotype in the clinical spectrum of FMF ${ }^{16}$.

\section{CONCLUSION}

This exceptional case constitutes a rare presentation of FMF with co-existing systemic PAN and APSGN. Since FMF is an autoinflammatory disease and streptococcal infections frequently trigger FMF attacks, all three conditions may be preceded by a streptococcal infection. The homozygous M694V mutation in our patient caused an augmented response to streptococcal antigens, leading to APSGN and PAN. This clinical presentation also confirmed the role of GAS in the etiology of systemic PAN.

CONSENT: Written informed consent was obtained from the patient's parents to publish this report in accordance with the journal's patient consent policy.

AUTHOR CONTRIBUTIONS: YÖA, BED and SAB were actively involved in the clinical care of the patient and wrote the manuscript.

ACKNOWLEDGMENTS: The authors wish to thank parents of the child in this case for their cooperation.

CONFLICT OF INTEREST: All authors declare that they have no competing interests.

\section{LEGENDS TO FIGURES}

Figure 1. a, b. The MIP images in abdominal CT angiographic data showing multiple microaneurysms in the peripheral branches of the left hepatic artery (white arrows).

\section{REFERENCES}

1. Sönmez HE, Batu ED, Özen S. Familial Mediterranean fever: current perspectives. J Inflamm Res. 2016 Mar 17;9:13-20. doi: 10.2147/JIR.S91352. PMID: 27051312; PMCID: PMC4803250.

2. Familial Mediterranean fever (FMF) in Turkey: results of a nationwide multicenter study. Medicine (Baltimore). 2005 Jan;84(1):1-11. doi: 10.1097/01.md.0000152370.84628.0c. PMID: 15643295.

3. Akpolat T, Akpolat I, Karagoz F, Yilmaz E, Kandemir B, Ozen S. Familial Mediterranean fever and glomerulonephritis and review of the literature. Rheumatol Int. 2004 Jan;24(1):43-5. doi: 10.1007/s00296003-0329-9. Epub 2003 Jun 27. PMID: 12835915.

4. Eison TM, Ault BH, Jones DP, Chesney RW, Wyatt RJ. Post-streptococcal acute glomerulonephritis in children: clinical features and pathogenesis. Pediatr Nephrol. 2011 Feb;26(2):165-80. doi: 10.1007/s00467-010-1554-6. Epub 2010 Jul 23. PMID: 20652330.

5. Grøndahl C, Rittig S, Povlsen JV, Kamperis K. Protracted Clinical Course of Postinfectious Glomerulonephritis in a Previously Healthy Child. Case Rep Nephrol Dial. 2016 Apr 14;6(1):70-5. doi: 10.1159/000445678. PMID: 27226969; PMCID: PMC4870938.

6. Ozen S, Ben-Chetrit E, Bakkaloglu A, Gur H, Tinaztepe K, Calguneri M, Turgan C, Turkmen A, Akpolat I, Danaci M, Besbas N, Akpolat T. Polyarteritis nodosa in patients with Familial Mediterranean Fever (FMF): a concomitant disease or a feature of FMF? Semin Arthritis Rheum. 2001 Feb;30(4):2817. doi: 10.1053/sarh.2001.19958. PMID: 11182028.

7. Eleftheriou D, Batu ED, Ozen S, Brogan PA. Vasculitis in children. Nephrol Dial Transplant. 2015 Apr;30 Suppl 1:i94-103. doi: 10.1093/ndt/gfu393. Epub 2014 Dec 30. PMID: 25550447.

8. Hernández-Rodríguez J, Alba MA, Prieto-González S, Cid MC. Diagnosis and classification of polyarteritis nodosa. J Autoimmun. 2014 Feb-Mar;48-49:84-9. doi: 10.1016/j.jaut.2014.01.029. Epub 2014 Jan 28. PMID: 24485157.

9. Yalçinkaya F, Ozçakar ZB, Kasapçopur O, Oztürk A, Akar N, Bakkaloğlu A, Arisoy N, Ekim M, Ozen S. Prevalence of the MEFV gene mutations in childhood polyarteritis nodosa. J Pediatr. 2007 Dec;151(6):675-8. doi: 10.1016/j.jpeds.2007.04.062. Epub 2007 Aug 28. PMID: 18035151. 
10. Samarkos M, Loizou S, Vaiopoulos G, Davies KA. The clinical spectrum of primary renal vasculitis. Semin Arthritis Rheum. 2005 Oct;35(2):95-111. doi: 10.1016/j.semarthrit.2005.05.004. PMID: 16194695 .

11. Ozen S, Anton J, Arisoy N, Bakkaloglu A, Besbas N, Brogan P, García-Consuegra J, Dolezalova P, Dressler F, Duzova A, Ferriani VP, Hilário MO, Ibáñez-Rubio M, Kasapcopur O, Kuis W, Lehman TJ, Nemcova D, Nielsen S, Oliveira SK, Schikler K, Sztajnbok F, Terreri MT, Zulian F, Woo P. Juvenile polyarteritis: results of a multicenter survey of 110 children. J Pediatr. 2004 Oct;145(4):517-22. doi: 10.1016/j.jpeds.2004.06.046. PMID: 15480378.

12. Eleftheriou D, Dillon MJ, Tullus K, Marks SD, Pilkington CA, Roebuck DJ, Klein NJ, Brogan PA. Systemic polyarteritis nodosa in the young: a single-center experience over thirty-two years. Arthritis Rheum. 2013 Sep;65(9):2476-85. doi: 10.1002/art.38024. PMID: 23754739.

13. Cengiz N, Demir S, Parmaksiz G, Temiz AK, Noyan A. Polyarteritis nodosa: a case presenting with renal mass. Eur J Pediatr. 2012 Dec;171(12):1859-60. doi: 10.1007/s00431-012-1812-7. Epub 2012 Sep 2. PMID: 22941495.

14. Eleftheriou D, Melo M, Marks SD, Tullus K, Sills J, Cleary G, Dolezalova P, Ozen S, Pilkington C, Woo P, Klein N, Dillon MJ, Brogan PA. Biologic therapy in primary systemic vasculitis of the young. Rheumatology (Oxford). 2009 Aug;48(8):978-86. doi: 10.1093/rheumatology/kep148. Epub 2009 Jun 17. PMID: 19535611.

15. Bakkaloğlu SA, Muzaç S, Akpek S, Söylemezoğlu O, Buyan N, Hasanoğlu E. Polyarteritis nodosa in a case of familial Mediterranean fever. Pediatr Nephrol. 2004 May;19(5):536-8. doi: 10.1007/s00467003-1390-z. Epub 2004 Feb 12. PMID: 14963762.

16. Grossman C, Kassel Y, Livneh A, Ben-Zvi I. Familial Mediterranean fever (FMF) phenotype in patients homozygous to the MEFV M694V mutation. Eur J Med Genet. 2019 Jun;62(6):103532. doi: 10.1016/j.ejmg.2018.08.013. Epub 2018 Aug 29. PMID: 30171907.

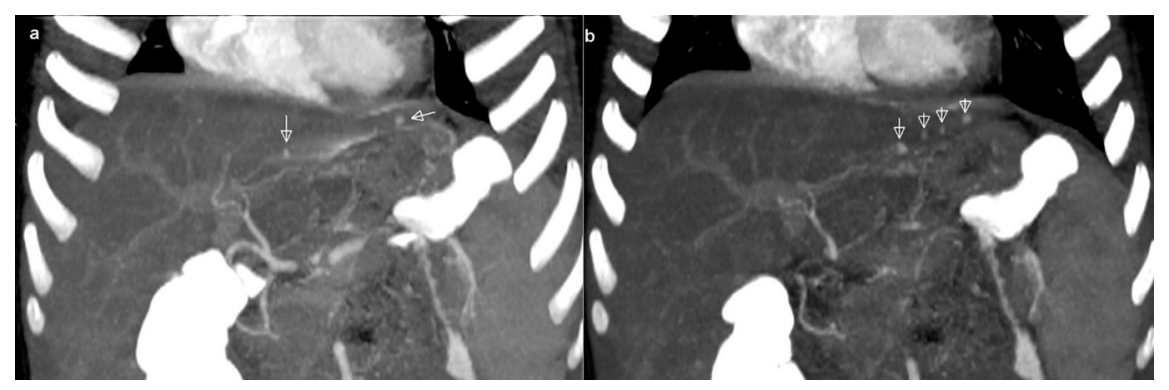

